\title{
СОВРЕМЕННЫЕ НАПРАВЛЕНИЯ ДЗ ДЛЯ МОНИТОРИНГА СОСТОЯНИЯ ОБЪЕКТОВ НЕФТЕДОБЫВАЮЩЕЙ ОТРАСЛИ
}

\author{
Александр Юрьевич Чермошенцев \\ Сибирский государственный университет геосистем и технологий, 630108, Россия, г. Новоси- \\ бирск, ул. Плахотного, 10 , кандидат технических наук, доцент кафедры фотограмметрии и ди- \\ станционного зондирования, тел. (383)361-08-66, e-mail: fdz2004@bk.ru
}

\section{Татьяна Алексеевна Чалкова}

Сибирский государственный университет геосистем и технологий, 630108, Россия, г. Новосибирск, ул. Плахотного, 10, аспирант, тел. (923)740-32-02, e-mail: tatyanach-2015@mail.ru

В работе рассмотрены современные направления дистанционного зондирования для мониторинга состояния объектов нефтедобывающей отрасли. грязнение

Ключевые слова: мониторинг, спутниковые снимки, обнаружение, разливы нефти, за-

\section{CURRENT TRENDS OF REMOTE SENSING FOR MONITORING THE STATE OF OIL PRODUCTION FACILITIES}

\section{Aleksandr Yu. Chermoshentsev}

Siberian State University of Geosystems and Technologies, 10, Plakhotnogo St., Novosibirsk, 630108, Russia, Ph. D., Associate Professor, Department of Photogrammetry and Remote Sensing, phone: (383)361-08-66, e-mail: fdz2004@bk.ru

\section{Tatyana A. Chalkova}

Siberian State University of Geosystems and Technologies, 10, Plakhotnogo St., Novosibirsk, 630108, Russia, Ph. D. Student, phone: (923)740-32-02, e-mail: tatyanach-2015@mail.ru facilities.

The article considers current trends of remote sensing for monitoring the state of oil production

Keywords: monitoring, satellite imagery, detection, oil spills, pollution

Важными вопросами космической науки и техники на сегодняшний день являются: развитие космических систем дистанционного зондирования Земли, создание новых, в том числе малых, космических аппаратов, систем наземной обработки космической информации и алгоритмов ее обработки. Эта сфера деятельности становится все более жизненно необходимой для социально-экономического развития страны, которое зависит от наблюдений Земли из космоса.

В современном мире особенное значение приобретает оценка состояния окружающей среды. Антропогенное воздействие, возникающее при постоянном увеличении техногенной нагрузки, в том числе аварийные разливы нефти и нефтепродуктов в процессе добычи, хранения и транспортировки, может приводить к катастрофическим последствиям. В связи с этим необходимо решать 
задачи по оперативному определению таких загрязнений, что является залогом их своевременной локализации и ликвидации.

Особое внимание в комплексной системе по обнаружению разливов нефтепродуктов отводится данным дистанционного зондирования Земли, поскольку обследование наземными средствами не всегда целесообразно и возможно и не может обеспечить оперативность и своевременность получения данных. Это определяет использование летательных аппаратов и аэрокосмических методов ДЗ как оптимальный метод мониторинга состояния таких объектов.

Космический мониторинг осуществляется по следующим направлениям:

- мониторинг мест сжигания попутного газа и инвентаризация факельных установок;

- мониторинг окружающей среды в пределах лицензионных участков (выборочные и сплошные рубки леса, контроль состояния просек, проливы нефти и др.);

- несанкционированный доступ в зону безопасности объекта;

- обнаружение аварий и оценка экологического ущерба;

- определение и мониторинг смещений объектов, обеспечивающих функционирование трубопроводов, происходящих в районах вечной мерзлоты и областях с повышенной сейсмоактивностью;

- мониторинг условий и контроль темпов землепользования на основе аэрокосмических данных для оценки эффективности рекультивации загрязненных земель;

- мониторинг ледовой обстановки в местах расположения буровых платформ арктических районов с помощью спутников - имеет важное значение в обнаружении участков трубопроводов, способных вызвать нежелательные последствия (включая оценку изменения вследствие изменения свойств грунтов оценку динамики низкотемпературного режима грунтов и результатов ее воздействия);

- мониторинг опасных природных процессов, таких как сели, оползни, землетрясения, вызванные, в том числе, техногенным воздействием [2];

- создание 3D-моделей местности, электронных карт, различной тематической направленности геоинформационных систем для богатых нефтью районов и др;

- использование данных Д3З при строительстве таких сооружений, как нефтехранилища, резервуары, а также нефтеперерабатывающие заводы [3]. И здесь получению необходимой информации кроме как с помощью современных космических средств дистанционного зондирования альтернативы практически нет.

Следует отметить, что, несмотря на высокий потенциал применения данных дистанционного зондирования, он пока не носит массового и системного характера. Основной причиной этого явления выступает отсутствие системы оперативного доступа к данным дистанционного зондирования Земли в России. Кроме того, можно отметить такие ограничения, как высокая стоимость получения данных с зарубежных космических аппаратов, отсутствие нормативно-правовой 
документации по стандартизации продуктов дистанционного зондирования и их применению [4].

Из практики применения космических снимков, наиболее частыми запросами пользуются архивные данные с пространственным разрешением от 10 до 30 метров, которые находятся в открытом доступе. В последние годы, помимо доступа через хранилища операторов данных систем, появились многочисленные веб-сервисы с простым и удобным для пользователя интерфейсом, которые позволяют не только выполнять поиск и получение данных, но и некоторые операции по расчету индексных изображений для предварительной оценки качества снимков. Тем не менее возможность получения данных в оптическом и радиолокационном диапазонах в короткие сроки для их комплексного анализа в настоящее время отсутствует. Главным образом это связано с недостаточной производительностью существующей группировки спутников ДЗ3. Однако наметившаяся тенденция развития группировок микро- и наноспутников, качество и характеристики данных с которых постоянно совершенствуются, позволяет спрогнозировать решение данной проблемы в ближайшее десятилетие [4]. В Российской Федерации первым успешным проектом может стать группировка спутников компании Success Rockets, которая предлагает собственные разработки не только в качестве носителей аппаратуры, но и средств вывода спутников на орбиту.

Среди объектов нефтегазодобывающей отрасли, которые требуют своевременного контроля, выделяются:

- новые районы, перспективные для разработки месторождений нефти и газа области, в том числе расположенные на шельфах;

- морские нефтедобывающие платформы;

- резервуары для хранения нефтепродуктов;

- нефтеперерабатывающие комплексы;

- трубопроводы;

- морской и наземный транспорт для перевозки нефти, нефтепродуктов и сжиженного газа и др. [5].

По скорости развития технологий и технических средств и методов дистанционного зондирования и обработки полученной информации спектр приведенных задач расширяется.

Авиационные средства экологического мониторинга создаются и используются в ряде развитых и развивающихся стран. В Российской Федерации основные предпосылки, определяющие необходимость развития методов дистанционного зондирования в нефтегазовой отрасли, обусловлены следующим:

- значительной протяженностью трубопроводов;

- большими площадями, на которых ведется разработка месторождений;

- месторасположением в труднодоступных районах, с суровыми климатическими условиями;

- значительным интересом и возможностями нефтедобывающих компаний в решении задач, стоящих перед отраслью [6]. 
Исходя из технических характеристик существующей аппаратуры дистанционного зондирования (ширина полосы обзора, пространственное разрешение, период обновления информации и др.), а также доступности автоматизированных алгоритмов обработки и представления данных, высокой вероятности обнаружения и правильной идентификации объектов, комбинация оптических и радиолокационных данных является наиболее эффективным средством для определения разливов нефти на водной поверхности. Работа бортовых датчиков и интерпретация результатов требует высококвалифицированного персонала, однако за счет комбинации данных их недостатки компенсируются. В таблице приведены типы и диапазоны работы данных дистанционного зондирования.

Данные дистанционного зондирования для обнаружения нефтяных разливов

\begin{tabular}{|c|c|c|}
\hline $\begin{array}{l}\text { Тип дат- } \\
\text { чика }\end{array}$ & $\begin{array}{l}\text { Диапа- } \\
\text { зон } \\
\text { дат- } \\
\text { чика }\end{array}$ & Признаки нефти, обнаруживаемые датчиком \\
\hline \multirow[t]{3}{*}{$\begin{array}{l}\text { Оптиче- } \\
\text { ский (пас- } \\
\text { сивный) }\end{array}$} & $\begin{array}{l}\text { Види- } \\
\text { мый }\end{array}$ & $\begin{array}{l}\text { Цвет / неконкретизированное поглощение (изменения } \\
\text { контрастов яркости в различных участках электромаг- } \\
\text { нитного спектра за счет различия спектральных отража- } \\
\text { тельных способностей), например, коррозия труб иден- } \\
\text { тифицируется по входящему в состав спектрального } \\
\text { компонента оксида железа }\end{array}$ \\
\hline & $\begin{array}{l}\text { Инфра- } \\
\text { крас- } \\
\text { ный }\end{array}$ & $\begin{array}{l}\text { Поглощение при определенной длине волны }(0,8 ; 1,2 ; \\
1,73 ; 2,3 \text { мкм) }\end{array}$ \\
\hline & $\begin{array}{l}\text { Тепло- } \\
\text { вой ИК }\end{array}$ & $\begin{array}{l}\text { Температура зоны разлива по сравнению с прилегаю- } \\
\text { щими областями (возникновение теплового контраста, } \\
\text { предопределенного разницей температур транспортиро- } \\
\text { вочного продукта и грунта, окружающего трубопровод) }\end{array}$ \\
\hline $\begin{array}{l}\text { Радиоло- } \\
\text { катор } \\
\text { (РСА) (ак- } \\
\text { тивный) }\end{array}$ & $\begin{array}{l}\text { Микро- } \\
\text { волно- } \\
\text { вый }\end{array}$ & $\begin{array}{l}\text { Изменения в неровностях поверхности из-за деформиро- } \\
\text { вания разлитой нефти (сужается спектр радиолокацион- } \\
\text { ных сигналов, отраженных от загрязненных участков } \\
\text { поверхности, или изменяются его корреляционные ха- } \\
\text { рактеристики) }\end{array}$ \\
\hline
\end{tabular}

Преимущества и ограничения технологий спутникового дистанционного зондирования необходимо рассматривать совместно со сценарием нефтяного разлива, поскольку ряд различных факторов может повлиять на общую целесообразность отдельного инструмента. Необходимо принимать во внимание следующие факторы:

- масштаб разлива (и прогнозируемая длительность);

- географическое расположение, например, вдали от берега или на суше;

- условия природной среды; 
- условия работы;

- тип разлитой нефти и тенденция ее распространения в процессе выветривания;

- проблемы логистики (например, доступ для развертывания технологии);

- нормативные и политические ограничения (включая управление и регулирование воздушного пространства и океана, а также локальные требования к технологиям);

- тип операций реагирования;

- условия и время, когда понадобится информация;

- легкость внедрения и организации различных ресурсов и типов информации.

Определение толщины и типа нефтяного разлива посредством анализа снимков - важная область исследований в сферах ликвидации нефтяных разливов и дистанционного зондирования, где требуется оптимальная комбинация датчиков, особые условия работы и опыт эксперта. Вне зависимости места установки (носителя) датчика, он должен определять различную толщину разлива, чтобы иметь возможность подсчета объемов разлива, а также повышения эффективности заблаговременного планирования и определения наиболее подходящих методов очистки.

Наиболее известные методики обнаружения нефтяных разливов с помощью средств дистанционного зондирования Земли, как правило, основаны на выявлении пленок на акваториях по данным радиолокационной съемки, либо на обследовании протяженных трубопроводов с помощью средств беспилотных летательных аппаратов [7]. Для полноценного анализа результатов таких наблюдений требуется создание специализированных геоинформационных систем и баз данных.

После проведения мониторинговых исследований, их результаты проходят предварительную обработку и в дальнейшем становятся основой для создания тематических карт и наполнения баз данных геоинформационных систем различной направленности, предназначенных для оценки текущей обстановки, выбора алгоритма определенных решений.

Основными источниками данных для создания геоинформационных систем на обширные морские акватории являются такие материалы, как навигационные карты, дополненные сведениями из региональных геофизических центров. Необходимая информация о глубинах водоемов может поступать из общедоступных моделей, таких как ЕТОРО-5 и ЕТОРО-2. Общая инфраструктура нефтедобывающего комплекса, включающая положение буровых платформ, может быть получена из ведомственных архивов, атласов и корпоративных баз данных. Таким образом, современная система должна обеспечивать интеграцию всех имеющихся в доступе пространственных данных, космических снимков, а также обеспечивать их корректную и непрерывную совместную работу в единой оболочке.

Для повышения надежности решения задач диагностики нефтяных трубопроводов целесообразно проводить многосторонний мониторинг несколькими видами съемки [2], такими как съемка в ультрафиолетовом диапазоне, многоспектральная, инфракрасная, радиолокационная и лидарная. 
На радиолокационных изображениях структурный рисунок изучаемых объектов прослеживается более четко за счет меньшего взаимодействия радиоволн с объектами растительного покрова. Но иметь возможность визуального дешифрирования затемненных участков недостаточно для эффективного применения радиолокационных снимков для целей обнаружения нефтяных разливов. Требуется применение системы автоматизированного обнаружения нефтяных пятен, основанной на пороговом значении яркости, которая будет способна обрабатывать большие площади без участия оператора. Это может быть реализовано в виде отдельного программного модуля, дополняющего уже существующий пакет обработки данных дистанционного зондирования или включенный в геоинформационную систему, при этом важно, чтобы результат был представлен в удобном для получения и последующего анализа виде. В цикле предварительных процедур по обработке снимка наиболее важны следующие операции: радиометрическая коррекция, атмосферная коррекция, геометрическая коррекция и ортотрансформирование. Затем предполагается процесс улучшения качества изображения с помощью спектральных преобразований, или так называемая настройка гистограмм изображения (линейное растягивание, нормализация, линеаризация), фильтрация, преобразование Фурье.

Большинство лицензионных участков расположено в широких пойменных зонах крупных рек и характеризуются значительной обводненностью и заболоченностью грунтов, многочисленными малыми и средними озерами. Поэтому для более контрастного отделения загрязненных нефтью и нефтепродуктами участков от водных объектов, производится подстройка гистограммы изображения снимков, загруженных в комбинации инфракрасного изображения, где на контрасте красных яркостных характеристик выделяются темно-серо-зеленые оттенки загрязненных нефтью областей с размытыми границами. В зависимости от поставленной задачи фильтрация поможет устранить шумы, усилить узнавание объектов, подчеркнуть структурные линии, сгладить изображение и др. Путем разложения изображения на множество пространственно-частотных компонент преобразование Фурье улучшает его качество, где для удаления шумов достаточно выявить периодичность их появления. Для идентификации нарушенных участков, отделения их от других объектов известны технологии спектрального синтеза, объединения и интерпретации каналов данных. К примеру, в комбинации «естественные цвета» на космических снимках, гари по цветовым тонам похожи на нефтяные пятна.

Обнаружение новых мест загрязнения земной поверхности, растекание и впитывание нефти в почву с течением времени, сокращение размеров нарушенных участков за счет самовосстановления и рекультивации можно осуществить с помощью автоматизированного анализа. Достаточно выполнить анализ синтеза разновременных каналов и производных изображений, чтобы оценить возникнувшие на снимке изменения. Построение мультивременных композитов применяется для поиска ситуационных изменений.

В современном мире одним из наиболее уязвимых сфер становится экология, что может являться серьезным препятствием для дальнейшего устойчивого 
развития человечества. Дальнейшая деградация природных экосистем негативно сказывается на биосфере, приводит к утрате ее целостности и ведет к необратимым последствиям для окружающей среды и жизни в целом. Преодолеть наметившуюся тенденцию кризиса можно лишь путем создания нового типа взаимоотношений человека и природы и создания новых средств мониторинга для предотвращения нефтяных загрязнений биосферы [9].

В Российской Федерации высокое качество жизни и здоровья ее населения, а также национальная безопасность могут быть обеспечены только при условии сохранения природных систем и поддержания соответствующего качества окружающей среды. Отсутствие единой государственной политики в области экологии, направленной на охрану окружающей среды, и, в частности, на борьбу с разливами нефти, приводит к тяжелым последствиям, приобретающим уже не единичный характер. Сохранение и восстановление природных систем должно быть одним из приоритетных направлений деятельности государства и общества. Россия играет ключевую роль в поддержании глобальных функций биосферы, так как на ее обширных территориях, занятых различными природными экосистемами, представлена значительная часть биоразнообразия Земли. Масштабы природно-ресурсного, интеллектуального и экономического потенциала нашей страны обусловливают важную роль в решении глобальных и региональных экологических проблем.

Таким образом, можно сделать вывод о необходимости совершенствования системы мониторинга различных экологических ситуаций, в данном случае ситуаций, связанных с нефтяными загрязнениями. Сохранение природы и улучшение окружающей среды являются приоритетными направлениями для государства и общества. Задачами, требующими скорейшего разрешения, являются создание единой государственной структуры, осуществляющей экологический мониторинг, и стимулирование исследовательской деятельности в области химического анализа компонентов окружающей среды вкупе с социальными программами, призванными информировать потребителей о насущных экологических проблемах.

Работа выполнена в рамках государственного задания Минобрнауки России (тема - «Разработка теории и технологических решений контроля состояния защитных сооружений при перекачке нефтепродуктов методами активного дистанционного зондирования», № 0807-2020-0002).

\section{БИБЛИОГРАФИЧЕСКИЙ СПИСОК}

1. Емельянова Т.А. Организация рационального использования и охраны земельных ресурсов северных территорий Российской Федерации (теория, методика, практика): Монография / Т.А. Емельянова. - М.: ГУЗ, 2004. С. 324.

2. Бондур В.Г. Аэрокосмические методы и технологии мониторинга нефтегазоносных территорий и объектов нефтегазового комплекса // Исследование Земли из космоса -2010. № 6. С. 3-17.

3. Космический мониторинг лицензионных участков [Электронный ресурс]. - Режим доступа: https://innoter.com/otraslevye-resheniya/neftegazovyy-kompleks/kosmicheskiy monitoringlitsenzionnykh-uchastkov/. 
4. Использование космических систем наблюдения в нефтегазовой отрасли О.П. Павлова, Д.Н. Севастьянов. Журнал "Бизнес" Спец. выпуск 1(2) 2007 г.

5. ZALAAEROGROUP. Беспилотные системы [Электронный ресурс]. - Режим доступа: http: // http: // zala.aero / category / applications / monitoring / neftegazoprovodov - mest - dobychi uglya/.

6. Аэрокосмический мониторинг объектов нефтегазового комплекса. Под редакцией академика В. Г. Бондура - М.: Научный мир, 2012. 558 с.: ил. +52 с. цв. ил.

7. Перспективные информационные технологии (ПИТ 2017): труды Международной научно-технической конференции / под ред. С.А. Прохорова. - Самара: Издательство Самарского научного центра РАН, 2017. - 1216 с.

8. Иванов А.Ю., Затягалова В.В. Картографирование пленочных загрязнений моря с использованием космической радиолокации и географических информационных систем // Исследование Земли из космоса, 2007, № 6.

9. Экологический мониторинг нефтяных загрязнений [Электронный ресурс]. - Режим доступа:. https://works.doklad.ru/view/67cI3iLIKbs/all.html.

(C) А. Ю. Чермошенцев, Т. А. Чалкова, 2021 